\title{
EL ESCAMOTEO DEL TERCER PAPEL DEL PATRIARCA RIBERA A FAVOR DE LA EXPULSIÓN DE LOS MORISCOS
}

\author{
RAFAEL BENÍTEZ SÁNCHEZ-BLANCO \\ Universitat de València
}

Fecha de recepción: noviembre 2008

Fecha de aceptación: abril 2009

El 6 de enero de 1611 fallecía el anciano don Juan de Ribera, Patriarca de Antioquía y arzobispo de Valencia durante más de cuarenta años. En el momento de su muerte la expulsión de los moriscos valencianos podía darse por concluida, al igual que la de los aragoneses y catalanes, y la de los de origen granadino dispersados por la Corona de Castilla a raíz de la sublevación y guerra de Granada. Quedaba solo por cerrar el proceso de deportación de los antiguos mudéjares castellanos, en particular los que vivían en el Reino de Murcia ${ }^{1}$.

El cronista Gaspar Escolano en las páginas finales de la segunda parte de su Década $a^{2}$ nos transmite su visión de la situación anímica por la que pasaba Ribera en vísperas de la muerte:

El Patriarca, arçobispo de Valencia, visto el laberinto en que quedava el Reyno [...], y que la nobleza y el pueblo le hazían cargo de todo como autor que él avía publicado ser de la salida de los moros y que havía estragado mucha parte de la afición y estima que le tenían los valencianos, empeçó a sentir carcoma en su coraçón [...] dio en una lenta calentura que vino a quitarle la vida día de los Reyes del año mil seyscientos y onze.

Y cierra su obra con la copia y traducción de la lápida latina conmemorativa de la expulsión que la ciudad de Valencia mandó hacer y que hoy se conserva en el Museo

1. Este trabajo se realiza contando con la ayuda de un proyecto financiado por el Ministerio de Ciencia e Innovación, titulado: «El gobierno, la guerra y sus protagonistas en los reinos mediterráneos de la Monarquía Hispánica» (HAR2008-00512).

2. Escolano, Gaspar: Segunda parte de la Década primera de la historia de la... ciudad y reyno de Valencia, Valencia:Pedro Patricio Mey, 1611, (edición facsímil publicada por el Departamento de Historia Moderna, Universidad de Valencia, 1972), cols. 2000-1. 
de Bellas Artes de Valencia. En ella se atribuía al Arzobispo el impulso que condujo a Felipe III y al duque de Lerma a tomar la decisión: flagitante et urgente Ioanne a Ribera; «Haziendo apretadas instancias para ello D. Juan de Ribera...»» ${ }^{3}$. Y para cerrar su historia, Escolano plantea en breves líneas la terrible situación en que quedaba el Reino de Valencia. Esto se publicaba en 1611.

El 13 de julio de ese mismo año, a los pocos meses del fallecimiento del Arzobispo, el jesuita P. Francisco Escrivá veía aprobada por el vicario episcopal, D. Baltasar de Borja, la primera biografía del Patriarca, que se publicaría al año siguiente, $1612^{4}$. Al final de su obra, copiaba, entre otros muchos documentos, los papeles que Ribera envió a Felipe III en 1601 y 1602 solicitando la expulsión de los moriscos, y que fueron utilizados, pocos años más tarde, como justificación ideológica principal de la medida.

La intención del libro, tal como el P. Escrivá manifiesta en el prólogo al lector, es alabar las virtudes del difunto para que sirvan de ejemplo a los fieles. Estamos, pues, ante una obra de exaltación de los méritos del biografiado. Esto no impide que el autor defienda la veracidad de lo que escribe: «Todo lo que sabía y podía decir, he dicho con toda verdad». El argumento básico que le respalda es el conocimiento que los lectores tienen de la vida de Ribera:

Aunque quisiera, como dice san Gregorio Nacianceno, no pudiera poner y añadir de mi casa nada, habiendo tan poco que murió y siendo aun vivos los que le conocieron, y estando como está el lector de por medio, como testigo y juez entre la verdad y lo que se dice; el cual, si fuere justo y bueno, aprobará las alabanzas verdaderas y reprobará las falsas.

Pues bien, la autoridad de Escrivá ha hecho que su versión de los «papeles» o memoriales dirigidos por el Patriarca a Felipe III en 1601-1602 se haya convertido en canónica, y que su número haya quedado fijado en dos. No hubiera habido motivo para dudar de la validez de la afirmación y de los textos aportados por el P. Escrivá, y como tales hubieran podido seguir a falta de encontrar los originales o alguna de las múltiples copias que Ribera envió a la Corte o de tropezar con algún documento de archivo, si no hubiera interferido la inocente y al tiempo impertinente pluma de Fr. Damián Fonseca. Y esta hubiera pasado posiblemente desapercibida sin la retorcida argumentación de su hermano de hábito Fr. Jaime Bleda, que hace honor al adagio excusatio no petita, acusatio manifesta. Este cuenta en la Corónica que, en septiembre de 1609, Fr. Damián Fonseca le pidió una copia del manuscrito de la Defensio fidei y de los papeles del Patriarca para llevarlos a Roma. Se queja amargamente Bleda de que Fonseca la utilizó por extenso en su obra sobre la expulsión de los moriscos, a pesar de que le había prometido no hacerlo, y además sin citarle suficientemente 5 . En cuanto al empleo que hizo de los papeles del Patriarca, ironiza Bleda diciendo que los había fragmentando

3. Ibíd.: cols. 2004-5.

4. ESCRIVÁ, P. Francisco: Vida del illustríssimo y excellentíssimo señor don Iuan de Ribera, patriarca de Antiochía y arçobispo de Valencia, Valencia: Pedro Patricio Mey, 1612.

5. FonseCA, Fr. Damián: Del giusto scacciamento de moreschi da Spagna, Roma: Bartholomeo Zannetti, 1611 (traducida al italiano por Cosimo Gaci). A esta temprana edición italiana siguió pronto la castellana: Iusta expulsión de los moriscos de España, Roma: Iacomo Mascardo, 1612. 
y reproducido tanto a lo largo de su obra que parece que sean mucho más extensos de lo que son. Puntualiza además: «Y porque yo de dos que son los papeles hize tres por yerro, él los llama - en el argumento y división de la obra, explica en nota - tres gravísimos memoriales». El argumento que utiliza para explicar que no son tres sino dos, y que él estaba equivocado, no es otro que la autoridad de Escrivá: «Como se puede ver en el libro de la vida del Patriarca escrita por el padre Escrivá», dice también en nota ${ }^{6}$.

El propio Bleda nos sitúa sobre la pista del problema de fondo que presentaban los memoriales de Ribera. El dominico, que quería defender su papel de principal instigador de la expulsión, criticó al Patriarca por propugnar que la expulsión comenzase por los castellanos y por su intento de salvar, al menos de momento, a los valencianos y aragoneses. Veía en ello una concesión a los señores interesados en no perder a sus vasallos moriscos. Ambos, Ribera y Bleda, llegaron a discutir el asunto. Por eso, y por lo que ponen «los dos papeles del Patriarca» se considera en condiciones de afirmar que este propugnaba la expulsión de los moriscos de la Corona de Castilla y defendía la conservación de los de la Corona de Aragón. «Esta es la verdad y como tal se escribió y imprimió en vida deste santo Prelado, y con su licencia y en su presencia, en mi Defensa de la fe, y los que después de muerto dicen otra cosa, no tratan verdad, escriben glosas contra el texto y es pura lisonja, la cual él en vida aborreció»»?

Pascual Boronat, por su parte, desde su postura radical argumenta, en contra de Bleda, que Ribera no se opuso a la expulsión de los moriscos valencianos por intereses materiales, sino que únicamente defendió que se pospusiera. Para ello debe cerrar los ojos ante las protestas que el Arzobispo hizo ante la Corte por no seguir sus recomendaciones, al enterarse a fines de agosto de 1609 de la decisión de expulsar a los valencianos. Protestas que fueron acompañadas del envío, de nuevo, de sus memoriales de 1601-1602. La postura de Boronat ante estos es especialmente oscura: él, que presume de hacer historia crítica basada en documentos, remite aquí a los textos impresos, habla solo de dos papeles o memoriales, y recurre al argumento de autoridad eclesiástica que los valoró en el proceso de beatificación ${ }^{8}$.

Frente a esta defensa a ultranza de la responsabilidad del Patriarca en la expulsión, considerada como algo positivo, Ramón Robres adopta la postura contraria. Partiendo de que la decisión obedece a motivaciones de índole política, como es la amenaza exterior, trata de diluir las manifestaciones del Arzobispo a favor de la expulsión, y pasa de

\footnotetext{
6. BleDA, Fr. Jaime: Corónica de los moros de España, Valencia: Felipe Mey, 1618, pp. 946 y 947. Hay edición facsímil: Valencia: Publicaciones de la Universitat de València, 2001, estudio introductorio por Bernard Vincent y Rafael Benítez Sánchez-Blanco.

7. Ibíd.: pp. 894-895. La Defensio se publicaría finalmente en 1610: Defensio fidei in causa neophytorum siue Morischorum Regni Valentiae, totiusque Hispaniae, Valencia: Juan Crisóstomo Garriz, 1610.

8. Boronat y BARRACHINA, Pascual: Los moriscos españoles y su expulsión, Valencia: Imprenta de Francisco Vives y Mora, 1901 (existe edición facsímil, con un estudio preliminar de Ricardo García Cárcel, Granada:Universidad de Granada, 1992). Trata el asunto en el capítulo II del segundo volumen.
} 
puntillas sobre los memoriales de 1601-1602 . La situación histórica, claramente distinta de aquella en que escribe Boronat, exigía una prudencia que D. Pascual no tenía.

En contra de lo dicho por Escrivá, aceptado por Bleda y recogido por Boronat, la existencia de tres papeles es reconocida sin el menor género de duda por el propio autor en una carta a Felipe III escrita en 1608. Responde a una pregunta del Rey: «Si sentís evidente y propto peligro de no poner remedio en este negocio, me avisaréis el que se os ofrece y conviene para todo». La contestación de Ribera remite a sus memoriales de hace seis años: «Sobre este cabo tengo representado a Vuestra Magestad quanto Nuestro Señor a sido servido darme a entender, por tres papeles que envié el año 601». A continuación resume el contenido de estos, diferenciando el primero, en que exponía «el peligro general que corría la Corona de España», y los otros dos en que especificaba los medios para ponerle remedio y respondía a las objeciones -«dificultades»-que podían plantearse ${ }^{10}$.

Resulta, pues, evidente que los famosos papeles fueron tres y no dos, como su primer biógrafo afirmó, y los demás siguieron, obligando a Bleda a rectificar en sus primeras afirmaciones, pero no a Fonseca, cuya obra había aparecido antes de la de Escrivá. Y creo que también es innegable que, por lo menos, Escrivá y Bleda manipularon la «verdad histórica» a la que apela Boronat tantas veces. El primero de forma deliberada y directa, metiendo la tijera sobre los memoriales de su biografiado. El segundo, aceptando como error propio lo que no le debía caber duda que era una manipulación, ya que reconoce haber tenido copias de los papeles. ¿Qué contenía el «tercer papel» que ya en el momento de la muerte de Ribera se consideraba inoportuno dar a conocer?

La respuesta exige una tarea de reconstrucción de su contenido a partir de dos fuentes principales: un amplio resumen realizado para las trascendentales reuniones del Consejo de Estado de 30 de enero de 1608 y de 4 de abril de $1609^{11}$, y, por supuesto, la obra de Fonseca en que se especifica que algunos pasajes citados corresponden al tercer papel. Todo ello, evidentemente, cotejado con el texto de Escrivá.

El documento de Simancas es, por supuesto, un resumen para leer a los consejeros; por tanto su fidelidad al original varía de unos pasajes a otros, en función de lo que el encargado de hacer el resumen considerara fundamental, lo que tampoco es indiferente. En efecto, como podremos ver las tijeras del que sinetiza el documento dejan fuera algunos párrafos significativos, de los que se hace eco, sin embargo, Fonseca.

9. Robres Lluch, Ramón: San Juan de Ribera, Patriarca de Antioquía, Arzobispo y Virrey de Valencia 1532-1611: Humanismo y eclosión mística, Valencia: EDICEP, 2002, pp. 441 y ss. La primera versión de la obra de Robres apareció en 1960.

10. AGS: Estado, 209. Publicado por Mestre, Antonio: «Un documento desconocido del Patriarca Ribera escrito en los momentos decisivos sobre la expulsión de los moriscos», en Estudios dedicados a Juan Peset Aleixandre, Valencia: Universidad de Valencia, 1982, pp. 737-739.

11. AGS: Estado, 212. Papeles que, por cierto, fueron ampliamente citados y utilizados por Pascual Boronat a lo largo de su obra. Sobre la política de Felipe III en estos años, véase: BENíTEZ, Rafael: Heroicas decisiones. La Monarquía Católica y los moriscos valencianos, Valencia: Institució Alfons el Magnànim, 2001, pp. 352-420. 
Un primer cotejo de los memoriales en los tres textos mencionados muestra que, salvo casos excepcionales en que el resumen introduce variaciones que habrá que analizar, este y Fonseca coinciden allí donde Escrivá se salta alguna frase o párrafo. Siempre, por supuesto, en los casos en que el resumen es suficientemente detallado como para realizar la comparación, lo que en ocasiones no ocurre, como veremos de inmediato. Es decir, Fonseca sigue más de cerca el original que se utilizó en el Consejo de Estado que Escrivá. Por tanto debemos darle más fiabilidad que al primer biógrafo.

Se hace así pues necesaria una edición crítica de los famosos memoriales, que debo reconocer no he encontrado en mi manejo de los papeles del Archivo de Simancas, sin que ello signifique, por supuesto, que no estén allí. En este trabajo me limitaré a estudiar el misterioso «tercer papel». Para ello reproduzco en apéndice el resumen de Simancas, indicando la correspondencia o discrepancia tanto con Escrivá como con Fonseca. Del cotejo surgen varios tipos de diferencias:

- Hay párrafos comunes a los tres textos.

- Pasajes que Fonseca no ha incorporado en su fragmentaria reproducción.

- Algunos de estos aparecen en los otros dos, pero los hay que faltan en Escrivá, por lo que solo contamos con el resumen para conocerlos.

- Párrafos que aparecen en Fonseca, y no en Escrivá, y que el documento de Simancas resume ampliamente.

-Otros que este último se limita sólo a enunciar sin permitirnos conocer su contenido, y para los que dependemos en exclusiva de Fonseca.

Como se ve, el juego de combinaciones es muy complejo, y no pueden considerarse inocentes y debidas al azar, sino todo lo contrario. Voy a detenerme, en especial, en lo que callaron tanto Escrivá como el propio resumen elaborado para los Consejeros de Estado. Dice así: ${ }^{12}$

Bastaría para persuadir desta resolución el descargo que della se sigue a la Real Conciencia de Vuestra Magestad, según lo arriba dicho, pero siendo tantos y tan importantes los provechos que la acompañan no se pueden dexar de representar para la mayor justificación de la causa. [De la expulsión de los castellanos] síguense grandíssimos provechos spirituales porque los prelados y curas saldrán del grave escrúpulo que tienen, y han de tener necessariamente si han estudiado y saben Teologia, baptizando a personas que saben que han de apostatar.

Item, instruye Vuestra Magestad en un copiosíssimo y convenientíssimo seminario gran número de sugetos, y esto sin costarle hazienda, antes ganándola, porque vendiendo los niños y niñas menores de siete años (que serán más de treynta y cinco mil) a christianos viejos, serán todos cathólicos, olvidarán la lengua y el hábito, aprenderán oficios y artes, y vendrán necessariamente a olvidar las ceremonias de Mahoma y a guardar las de nuestra santa fe.

Y poco después -sigue copiando Fonseca-: No dexa de ser de mucha consideración para este mismo provecho spiritual, en los mayores, el ponerlos Vuestra Magestad por esclavos en las galeras o en las minas, y el venderlos a christianos viejos, porque con esto se conseguirá lo que muchos han desseado y juzgado por grande remedio para la reduc-

12. FONSECA, Damián: Iusta expulsión..., pp. 187-189. 
ción de estos, que es mezclarlos entre christianos viejos, para que assí no pudiessen usar de sus ceremonias, aviendo de ser vistos, y para mezclarlos por diversas partes. Adviértase en este lugar que de ninguna manera convendría vender en España los hombres o mugeres, porque sería de grande perjuizio para los niños que se han de criar en ella.

Tratando después de los bienes temporales que se conseguirían con esta expulsión, dize lo siguiente: Aunque las utilidades y provechos temporales son considerables por sí solos, en razón de justicia lo deben de ser quando van arrimados a las utilidades spirituales, y en unos tiempos y ocasiones más que en otras, etc. Y después de aver encaresido quán necessario era que el Patrimonio Real estuviesse rico y desempeñado, y que Su Magestad se hallasse con alguna buena cantidad de dinero para la defensa de sus reynos, las quales dos cosas juzgava que se avían de poner debajo de un mismo predicamento por concurrir en ellas una misma justificación, añade estas palabras:

Parece que en tiempo que se ofrece esta necessidad tan precisa no permite la justicia distributiva que Vuestra Magestad se quiera valer de sus vasallos cathólicos y fieles, cuyas haziendas y vidas han de estar perpetuamente dedicadas y consagradas a su real servicio $y$ al beneficio y defensa de sus reynos, dexando libres y ricos a los hereges y enemigos de V. M. y de sus reynos, cuya hazienda sabemos cierto que está dispuesta y consignada para daño de Vuestra Magestad y de sus vasallos. Especificando más esto se representa que vendrán a ser de mucha consideración las cantidades que entrarán en el fisco de Vuestra Magestad por medio desta santa esecución de justicia, porque como se ha dicho, y ahora se dize de nuevo, Vuestra Magestad puede tomar por esclavos y esclavas, assí para su servicio como para venderlos a otros, todos estos, sin escrúpulo de conciencia alguna. $Y$ la cantidad de hombres, mugeres y moços sanos será tanta que, después de proveydas las galeras y minas, se podrán vender en Italia los demás.

Iten, los niños y niñas de siete años abajo se venderán en España a buenos precios, y se comprarán con gusto, y serán también en gran cantidad. Esto no solo puede Vuestra Magestad hazerlo, pero está obligado en conciencia, y a no imbiar estos niños con sus padres. Y la servidumbre que les impone vendiéndolos no se debe de tener por pena, antes beneficio suyo debido al bautismo que recibieron.

Demás de lo que se sacare por estos dos caminos, queda el mucho tesoro que ay en poder destos y las propiedades que han comprado y las tiendas y grangerías que tienen, que será necessariamente de mucha estima y valor. En fin, halla Vuestra Magestad un gruesso socorro de sus enemigos, en tiempo que se tiene servido de los pequeños que sus vasallos ofrecemos. En todo lo dicho no se puede poner duda alguna ni en razón de conciencia ni en razón de gobierno.

En definitiva, lo que pareció conveniente esconder, tanto a Escrivá como al redactor del resumen para el Consejo de Estado ${ }^{13}$, fue la propuesta de esclavizar a los moriscos, incluyendo a los niños y niñas menores de siete años, que el Patriarca planteaba como factible e incluso conveniente para las arcas de la Monarquía, y como estímulo indudable para animar a Felipe III y sus consejeros a aprobar la expulsión. Constatado esto, quedan, sin embargo, por explicar las causas de la ocultación.

Para el jesuita, que escribe con la finalidad de destacar la virtudes cristianas de Ribera, es muy posible que no le pareciera nada conveniente presentar como meritoria

13. Este se limita a hacer una mención mínima que no aclara nada, como puede verse en el punto 7 del apéndice. 
la idea de unir el interés material con el espiritual a la hora de justificar la expulsión, y menos cuando el medio principal era la venta de cristianos como esclavos, por muy apóstatas que fueran. La propuesta de vender a los niños menores chocaba, en particular, con diversas cuestiones de principio como la responsabilidad personal. Ya con ocasión de la guerra de Granada se había declarado que no podían ser considerados esclavos, y que solo podían darse en custodia, para aprovecharse de su servicio temporalmente, hasta la mayoría de edad. Poco después, en el momento de la expulsión, el problema de qué hacer con los niños provocará duras discusiones entre los teólogos y los generales. El Patriarca defendió entonces que se retuviera a los niños; algo que ya había propugnado en el «segundo papel», aun reconociendo que había «personas doctas» que opinaban que los menores de siete años podían venderse como esclavos. Sin embargo, ante la imposibilidad material y política de quitar los niños a sus padres hubo que aceptar su emigración, aunque, pronto, el malestar de Roma ante el envío de inocentes criaturas bautizadas a tierras de infieles obligó al Gobierno a forzar a los padres que quisieran llevárselos a partir para tierras cristianas. En este contexto, la propuesta de Ribera en el tercer papel, además de contradictoria con lo que en el segundo memorial había propuesto, no era políticamente correcta y explica el escamoteo a que la sometió su biógrafo.

A fines de 1607 o principios de 1608, momento en que se preparan los materiales y resúmenes para la fundamental reunión del Consejo de Estado de 30 de enero, la cuestión no había alcanzado todavía ese grado de conflictividad. Me inclino a pensar que no era la esclavitud en general, ni la de los niños en particular, lo que Lerma, impulsor sin duda de la discusión, quería sustraer al debate. Por otra parte, el resumen del «segundo papel» no había ocultado la posibilidad de esclavizar a los niños, opinión que el Patriarca ponía aquí en boca de «hombres doctos» ${ }^{14}$. Lo que no le interesaba al Valido era plantear la expulsión como una operación que buscaba un beneficio material inmediato. Su objetivo era convencer al piadoso Monarca y al sector más duro del Consejo de Estado que las cesiones de principios en la tregua que se negociaba con los rebeldes de las Provincias Unidas en el tema de la soberanía y en el abandono a su suerte de los católicos holandeses se compensaban con una heroica decisión en defensa del catolicismo. La consideración de ventajas materiales no convenía plantearla, por el momento.

Por otra parte la esclavitud de los moriscos había dejado de ser un tabú desde la guerra de Granada. Los excesos de los sublevados contra personas e imágenes sagradas, la violencia con que se dio muerte a curas y a cristianos viejos en bastantes lugares de la Alpujarra, por una parte, unidas a las necesidades bélicas por la otra, ya que los soldados se movían principalmente bajo el señuelo del botín, cuyo componente

14. El texto de Escrivá recoge la idea en la página 373. En cambio queda diluida en el resumen la propuesta de Ribera de someter a esclavitud a los que parecieren necesarios para las galeras o las minas de las Indias: «Podrá Su Magestad tomar los que fuere servido para sus galeras y minas, sin escrúpulo»; la palabra 'esclavos' ha desaparecido. Cf. con EsCRIVÁ, P. Francisco: Vida ..., p. 381. 
principal eran las esclavas y esclavos, todo ello obligó a autorizar la cautividad de los moriscos.

La amenaza de la esclavitud perseguirá a los granadinos que intentasen volver a su tierra de origen, y más tarde se estudiará como una solución global al problema que los deportados por Castilla planteaban. El propio Valido había defendido la medida. En efecto, a comienzos de 1599 se había tratado en el Consejo qué hacer con los granadinos dispersos por Castilla. En esta ocasión, el todavía marqués de Denia se manifestó partidario de deportarlos a Berbería, salvo a los niños que podrían educarse en seminarios. De entre los útiles se podrían tomar esclavos y galeotes. Los bienes se les confiscarían. Los otros miembros de la junta se opusieron a la propuesta, aunque no a que el Rey consultara con su confesor si sería lícito condenarles a muerte por su islamismo y si, como alternativa, se les podría esclavizar y confiscar los bienes. Aunque su consejo es que los granadinos se saquen de las ciudades y se distribuyan por lugares de entre cincuenta y quinientos, o como máximo mil vecinos, de forma que no supongan más del $2 \%$ del total de la población, y que se ocupen de la labranza y no de actividades comerciales. El Valido se opone argumentando que el reparto no solucionaba de raíz el problema ${ }^{15}$.

Como se observa, la idea de esclavizarlos como alternativa a medidas más radicales estaba encima de la mesa de la discusión y había dejado de considerarse un tabú. En definitiva, para muchos el morisco había perdido su consideración de cristiano y pasado a ser calificado de moro, y como tal transformado en objeto de cautiverio. La descristianización que el empleo del término 'moro' implicaba tenía consecuencias mentales y prácticas importantes.

Finalmente, Felipe III, llegado el momento de la expulsión, se negó a aceptar las propuestas de esclavitud. En las primeras instrucciones que se redactan para D. Agustín Mexía como encargado supremo de la deportación de los moriscos valencianos, se decía que, aunque se había aceptado que la esclavitud de los moriscos era lícita, no quería que se pensara que los expulsaba por el beneficio que podía obtener ${ }^{16}$. Se justifica así, con este comportamiento regio, la conveniencia expresada antes de no incluir en el resumen para la discusión en el seno del Consejo de Estado los polémicos puntos del memorial del Patriarca sobre las ventajas materiales de la deportación.

El otro asunto que Escrivá omite, y que conocemos a través del resumen del Archivo de Simancas -en este caso muy amplio (véanse los puntos 20 a 22 en el apéndice)-, es también significativo de la actitud del jesuita. En ellos, Ribera denuncia

15. AGS: Estado, 165 (publicado por BoronAt, Pascual: Moriscos, I, pp. 388-389). Hubo una primera junta el 30 de enero, y después de unos días de reflexión se volvieron a reunir el 2 de febrero.

16. «Está bien que llevéis entendido que si mis galeras se hallaren con necesidad de chusma al tiempo que se echaren estos moriscos de Valencia [...] se tomen dellos los que pareciere son precisamente menester por buenas vollas y no por esclavos en ninguna manera, pues no conviene que se entienda que en esto ha habido otro fin que sacarles del reyno por las causas que a ello me han movido, no obstante que la menor pena que a los más teólogos ha parecido que se devía dar a esta gente era que fuesen tomados por esclavos». AGS: Estado, 2.638B, ff. 16-21, punto 13; s.f., anteriores al 4 de agosto 1609. 
directamente a los malos consejeros que «por adulación [... y] pretendiendo ganar gracias» no dicen al Rey los graves peligros que corre España. La crítica política que su biografiado hacía, bien es verdad que en un documento privado, no parecía conveniente hacerla pública. Interpreto, también, en este sentido, la supresión que en el punto 15 realiza, eliminando la referencia a «algunos nobles» que se dejaron llevar por el mal ejemplo de los moriscos: entre otros podía sentirse aludido, en sus antepasados, el recién creado conde de Carlet. ${ }^{17}$

$$
* * *
$$

Si bien D. Juan de Ribera no fue el responsable de la decisión de expulsar a los moriscos, y se opuso a que se comenzara por los valencianos, sus tres «papeles» de 1601-1602 fueron utilizados como justificación ideológica llegado el momento. Es necesario, por tanto, estudiarlos en su contenido originario y analizar las formas en que fueron manipulados. Es lo que se ha intentado hacer aquí al recuperar el tercero de los memoriales, cuya existencia y parte de su contenido fue ocultado intencionadamente por el P. Escrivá.

\section{APÉNDICE \\ RESUMEN DEL TERCER PAPEL DEL PATRIARCA}

AGS, Estado, 212, exp. s.n., ff. 36 v.-40.

En el tercero papel pone quatro conclusiones:

1.- La primera, que Su Magestad en consçiencia so pena de peccado mortal está obligado, por ser Rey, a cuydar y atender al bien de sus Reynos y sustentarlos por medios necessarios y convinientes, en paz y prosperidad spiritual y temporal ${ }^{18}$.

2.- La segunda que se sigue necessariamente de la primera, siendo como es evidente y notorio el peligro que España tiene de padecer gravíssimos daños spirituales y temporales por haver en ella tantos enemigos de Dios, de Su Magestad y suyos, está $\mathrm{Su}$ Magestad obligado en consciençia a prevenir este daño, de la misma manera que lo staría a oponerse al Turco, porque la misma obligación que corre de oponerse a los enemigos (f. 37) de fuera, essa misma corre de assegurarse de los de dentro. Y el peligro destos es evidente por lo que atrás se a dicho, y porque si agora no son tantos como nosotros dentro de poco tiempo serán más.

3.- Tercera conclusión es que estando Su Magestad obligado en consçiençia y so pena de pecado mortal a poner los medios necessarios para librar a España de tan evidentes peligros, lo está también a sacar della todos estos enemigos suyos por ser este el

17. Quien a principios de 1610 había pedido información a la Inquisición de Valencia sobre el proceso de su padre (AHN: Inquisición, libro 333, ff. 41v, y 58v.). El señor de Carlet, Don Francisco de Castelví, había salido como penitenciado en el auto de fe de 25 de julio de 1571 (Ibíd: lib. 912, f. 492v.-493). En el mismo auto fue reconciliado «por la secta de Mahoma», D. Luis Pallás, señor de Cortes.

18. Los puntos 1 a 5 faltan en Escrivá pero están recogidos en FONSECA, Damián: Iusta expulsión..., pp. 186-187 y 162, de forma algo más extensa que en el resumen. La numeración de los puntos no existe en el original y ha sido introducida para facilitar las referencias. 
único medio que ay para alcançar este fin, de tal manera que ningún otro puede haver, como se prueva en el segundo papel.

4.- Quarta conclusión, que para sacar a estos de España el mejor, más conveniente, más breve, más suave y más provechoso camino es desterrarlos della de una vez, compeliéndolos a salir todos. Y esta conclusión está provada en el segundo papel.

5.- Síguese de las quatro conclusiones passadas una proposición firme y cierta, conviene a saber, que Su Magestad como Rey christiano está obligado a sacar estos de España.

6. Refiere lo que dice en el mismo papel, que este no es camino nuevo sino muy usado y platicado y las causas que justifican la execuçión y que no es menester proceder con citación y los demás términos de justicia, porque es común resolución de los doctores que en los delictos notorios no son necessarios ${ }^{19}$.

7.- Torna a reyterar los provechos que se seguirán desta resolución, que quedan referidos atrás ${ }^{20}$. También apunta el provecho que de la execución se sacará, de que trató en el segundo papel y responde a las difficultades que se pueden oponer en esta forma:

8.- La primera ${ }^{21}$ es decir que por ser estos (f. 37v.) baptizados la Yglesia está obligada a compelerlos para que guarden la fe de Nuestro Señor Jesuchristo y que assí no deven ser desterrados sino compelidos a que sean cristianos. Respóndese a esto que la Yglesia los a compelido por muchos y largos años con las armas que tiene y, desengañada por lo pasado de que no son de provecho en estos las tales compulsiones, es visto remitirlos a la compulsión temporal, como lo haze quando relaxa. Y assí, mereciendo todos estos pena de relaxaçión por ser apóstatas pertinazes y dogmatistas, deve remitir al braço seglar el castigo y solo se pretermite la forma judicial por no ser necessaria, como está dicho. Confírmase esta respuesta con el exemplo que tenemos en Flandes y Françia donde la Yglesia no trata de compeler a los hereges con execuçión de las penas que les están impuestas por derecho antes los dexa estar porque no puede más. $\mathrm{Y}$ es cierto y indubitado que si aquellos reyes degollassen a todos los hereges que ay en sus reynos, la Yglesia se lo agradecería y alabaría, como se ve por infinitas historias, y que si los tales reyes pudiessen echar de sus reynos los hereges, degollándolos o desterrándolos, y no lo hiziessen sería culpa notable suya y poco zelo de la religión. Lamentamos pues y con razón aquellos reyes y reynos por hallarse ocupados y presos de infieles, y no vemos (f. 38) que vamos a passos contados a incurrir en el mismo daño por el excesivo número destos, y que si dexamos de echarlos quando podemos nos castigará Dios Nuestro Señor en que quando queramos no podamos, antes seamos echados dellos.

19. Este punto falta en Escrivá y está mucho más extenso en FONSECA, Damián: Iusta expulsión ..., p. 413.

20. Hay algo tachado que no se lee, sobre lo que parece haber escrito: atrás. Este punto falta en Escrivá y conoce un amplio desarrollo en FONSECA, Damián: Iusta expulsión..., pp. 187-189. Han sido transcritas en el texto

21. A partir de este punto y hasta la mitad del n. 20 está recogido en las páginas 392 a 397 de Escrivá. 
9.- Dízese más que el príncipe está obligado, por lo dicho al principio, a proveer de remedios para la seguridad de sus reynos, y assí puede y debe usar de los remedios que le da el derecho divino y humano, sin empacharse en los medios eclesiásticos, y de la manera que es lícito ahorcar a uno destos quando mata a un hombre aunque la Yglesia lo pretende compeler a que sea christiano, de essa mesma manera puede degollar a todos estos por ser prodictores y maquinadores, tanto más desterrarlos. Lo que no es en manera alguna contravenir ni impedir los procedimientos de la Yglesia, antes bien, ayudar y favorecer al más exacto cumplimiento dellos ${ }^{22}$.

10.- La segunda difficultad que se puede ofrecer, y la que parece que en todo este negoçio es única, es dezir: desterrar a estos es lo mismo que dexarlos yr a ser moros porque sabemos que se yrán a los lugares de moros y assí parece que en alguna manera cooperamos para su eregía ${ }^{23}$.

11.- A esto se responde con la misma facilidad que a lo passado, y primero dize que no es necessaria conseqüençia del destierro yrse a tierras de moros, pues ay otras provincias de christianos donde pueden yr. Y si ellos lo son harán lo que hazen otros christianos que Su Magestad manda desterrar, y si no lo hazen será no por ser desterrados sino por ser moros.

12.- (f. 38v.) Dízese más, viniendo a la sustancia de la difficultad, que estos (como se presupone) son proditores de España y maquinadores del daño público y por ello merecen pena de muerte, de tal manera que no se excedería en justicia y consciençia degollándolos a todos, luego con más razón no se excede usando de pena menor.

13.- Item, estos podrían ser muertos en guerra justa, luego también pueden ser muertos en defensa justa y, mucho más, desterrados.

14.- Item, que la charidad no le obliga a que se dexe matar de uno destos, aunque se sabe que es moro y se a de yr al infierno, luego tampoco estará obligado a no deffenderse del aunque sepa que se a de yr a Argel.

15.- Item, estos son moros estando entre nosotros y nos consta que lo son, pues menos daño es que lo sean en Túnez donde cessa el mal ejemplo que dan a los christianos y la ocasión de que algunos christianos viejos ${ }^{24} \mathrm{y}$ aun nobles degeneren como se ha visto en nuestros tiempos.

16.- Iten, que no devemos con daños públicos, espirituales y temporales nuestros prover al daño destos tanto más constándonos que sin provecho dellos padecemos los dichos daños.

17.- Que sobre todo lo dicho y lo que se pudiere decir se levanta aquella consideración que es eminente a todas y como gigante en medio dellas dexando a todas las que se podrían representar derribadas y deshechas: Su Magestad es rey y señor de España y por el consiguiente obligado a deffenderla, conservarla y guardarla como a la cabeça de su real corona; ella se halla, en tanto que estos duran en su compañía, en evidentíssimo

22. FONSECA, Damián: Iusta expulsión ..., p. 405.

23. Los puntos 10 a 16 en FonSECA, Damián: Iusta expulsión ..., p. 416.

24. En EsCrivÁ, P. F.: Vida ..., p. 395, el final del punto dice: degeneren y lo dexen de ser. 
peligro por las razones dichas en el primer papel. Este peligro es tan notorio y evidente que no se puede dexar de ver y tocar con las manos y para evitarlo no ay ni puede haver otro medio sino echarlos luego. Su Magestad está obligado (f. 38v.) en consçiençia y so pena de pecado mortal y de estar olvidado de la conservación y prosperidad de su Real Corona a quitarlos de España.

18.- No dize de los daños espirituales y temporales que resultarían si (lo que Dios no permita) viniesse a perderse España como estos lo desean, lo esperan y lo pronostican, porque no çufre el coraçón de un cathólico pensar en los ynumerables daños de la fe, ni el de un fiel vassallo de su Rey en la total ruyna de su Corona que se yncurrirían, pero es bien que sirva esta consideración para contraponerla a las dos difficultades que se an representado. Tememos no se vayan los que son moros a vivir entre los moros y no tememos que los que son christianos y lo fueron sus antepasados sean compelidos a ser moros y que los templos y sanctuarios se profanen y, finalmente, que se sigan los males que refieren las historias quando estos tomaron a España.

19.- Dize que tiene miedo de haverse alargado en esto pero mayor es la confianza de que Su Magestad con su admirable begninidad y clemencia recivirá la voluntad deste su humilde y fidelíssimo capellán considerando que para lo que dize ningún fin le puede mover sino el desnudo deseo del servicio de Nuestro Señor y de Su Magestad.

20.- Y este mismo deseo le da atrevimiento a supplicar a Su Magestad, hincado de rodillas y de ojos ante sus reales pies, sea servido de mandar tomar breve resolución en este gravíssimo y importantíssimo caso $^{25}$ y no creer a los que le dixeren que no corre peligro España porque sin duda los que dixeren no lo creen, antes por adulación deshazen los peligros y quitan los cuydados, pretendiendo ganar gracias contra lo que deven a su real servicio y al beneficio de su patria.

21.- (f. 39v.) Quéxase Dios grandemente por un propheta de los que dezían a su pueblo que todo estava seguro y pacífico y que no havía de qué temer y dize: ¡Ay de vosotros que encubrís los daños como lo hazen los malos albañiles en las paredes ruinosas y desmoronadas, enxalvegándolas con cal porque parezcan sanas y se cubran los peligros de ruyna, yo (dize) derribaré la pared que vosostros procurastes encubrir y la ygualaré con el suelo para que se vea vuestra mentira y satisfaré a la indignación justa que tengo assí contra la pared como contra los que la an encubierto y dado por segura no estándolo!

22.- De lo qual se collige que este negocio no es para entregarse a muchos porque siempre huvo en el mundo poco de lo bueno, demás que el secreto es muy necessario.

23.- Buelve ${ }^{26}$ a dezir que la brevedad de la resolución piden a gritos los daños corrientes y los peligros evidentes de otros mayores, y assí cada día la dilación trae grandes ynconvinientes, principalmente haviendo tanta ynconstancia en las cosas humanas y pudiéndose justamente temer que de un día a otro se pueden offrecer, en tan grande máquina como es la de la corona de Su Magestad, ocassiones que nos embara-

25. A partir de aquí y hasta el punto 22 inclusive, falta en Escrivá.

26. De aquí hasta el final se recoge en ESCRIVÁ, P. Francisco: Vida ..., pp. 398-399. 
cen el tiempo y ocupen las fuerças. Y el negocio corre liso, sin scrúpulo de consçiençia, sin daño público ni particular, sin offensa de los reynos, antes bien al contrario con obligación de consciençia, con aprovación pública y general aplauso y agradescimiento de los vasallos; es justo, conviniente y provechoso assí en sí mismo como en los medios, con él assegura Su Magestad su reyno y corona, libra a los vasallos y fieles de la opresión questos les hazen quitándoles la comida y sustento (f. 40), enriquece su patrimonio real y assí no pide larga consultación ni da lugar a tardanza. Y por remate de toda esta materia se atreve a dezir a Su Magestad que quando considera la fuerça que a sentido en sí para haver de proponer a Su Magestad lo que en esto a dicho, siendo naturalmente retirado y haviendo crecido esta ynclinación suya con la edad y con las justas ocasiones, ve que anda en este negocio la mano de Dios Nuestro Señor y que a querido por medio de un instrumento echado al rincón dezir a Su Magestad su voluntad y apercevirle para mayor justificación de su causa con deseo paternal del bien y prosperidad spiritual y temporal de Su Magestad y de España, y assí confía en su misericordia que governará las sanctas actiones de Su Magestad al cumplimiento desta su voluntad. 